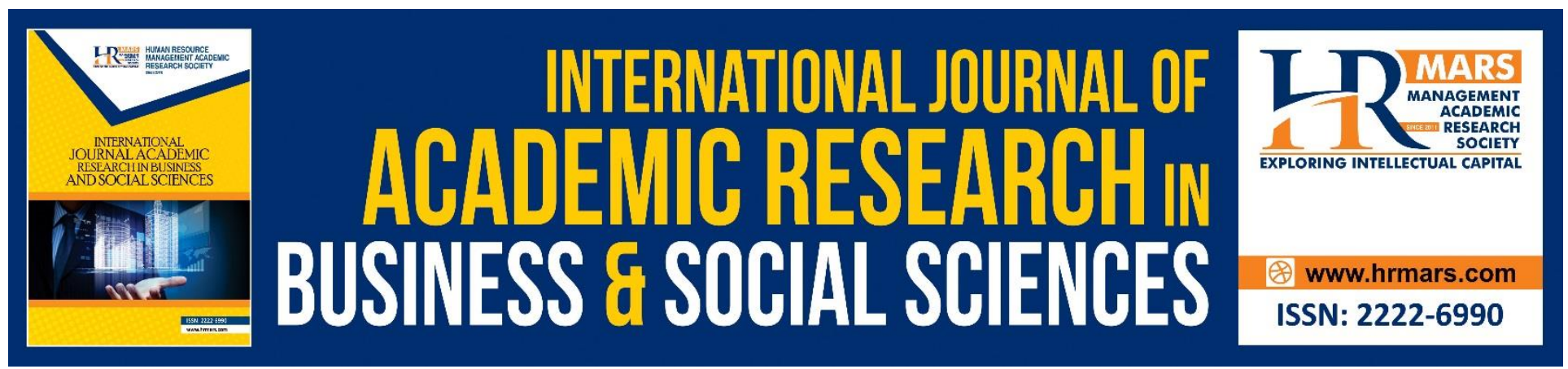

\title{
Brand Relations in Social Media: A Research on Turkish Dairy Sector
}

Caner Dincer

Banu Dincer

To Link this Article: http://dx.doi.org/10.6007/IJARBSS/v8-i12/5179

DOI: $10.6007 /$ IJARBSS/v8-i12/5179

Received: 22 Nov 2018, Revised: 25 Dec 2018, Accepted: 29 Dec 2018

Published Online: 30 Dec 2018

In-Text Citation: (Dincer \& Dincer, 2018)

To Cite this Article: Dincer, C., \& Dincer, B. (2018). Brand Relations in Social Media: A Research on Turkish Dairy Sector. International Journal of Academic Research in Business and Social Sciences, 8(12), 1144-1152.

\section{Copyright: (C) 2018 The Author(s)}

Published by Human Resource Management Academic Research Society (www.hrmars.com)

This article is published under the Creative Commons Attribution (CC BY 4.0) license. Anyone may reproduce, distribute, translate and create derivative works of this article (for both commercial and non-commercial purposes), subject to full attribution to the original publication and authors. The full terms of this license may be seen

at: http://creativecommons.org/licences/by/4.0/legalcode

Vol. 8, No. 12, 2018, Pg. 1144 - 1152

http://hrmars.com/index.php/pages/detail/IJARBSS

JOURNAL HOMEPAGE

Full Terms \& Conditions of access and use can be found at http://hrmars.com/index.php/pages/detail/publication-ethics 


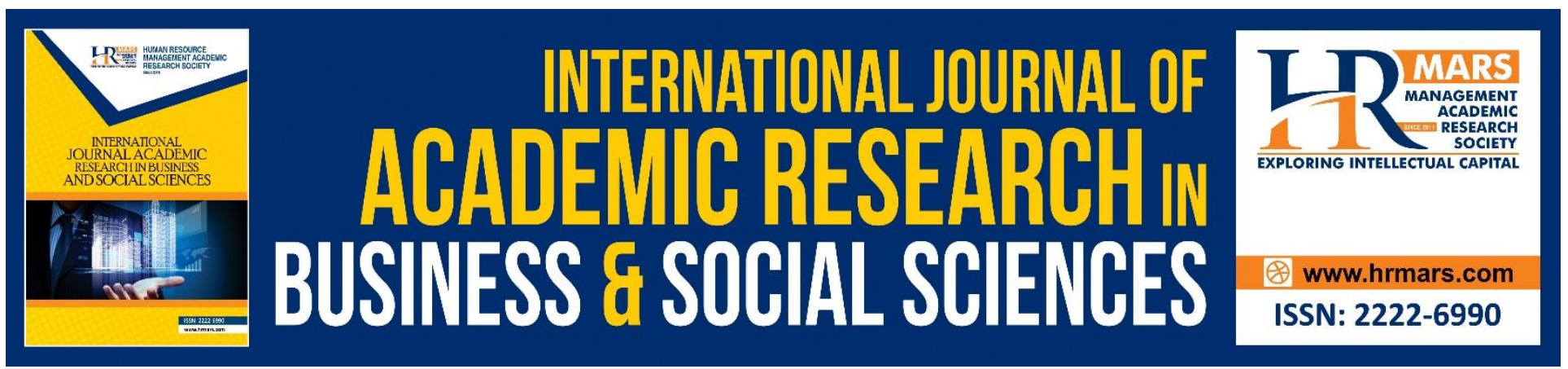

\title{
Brand Relations in Social Media: A Research on Turkish Dairy Sector
}

\author{
Caner Dincer \\ Faculty of Economic and Administrative Sciences, Department of Business Administration \\ Galatasaray University, Turkey. \\ Email: cdincer@gsu.edu.tr \\ Banu Dincer \\ Faculty of Economic and Administrative Sciences, Department of Business Administration \\ Galatasaray University, Turkey. \\ Email: bdincer@gsu.edu.tr
}

\begin{abstract}
Social media enables companies to promote their brands and products on online social platforms. Companies can create brand pages on social networking sites to develop consumer-brand relationships. There is a little research on the understanding of social media communication and how it can be used to engage the consumers especially by the dairy industry. The relationship between the consumer and the brand relationships through social media platforms needs to be investigated to understand dairy products brand efforts and to shed light to the structure of the data available, the design and delivery of social media content in the dairy industry.

This paper tries to guide further academic investigation on the topics of social media and especially the consumer engagement in the dairy industry using social media data available through Facebook. The paper will add to the knowledge in social media and engagement by identifying the main communication strategies used by dairy brands on Facebook, with engagement rates and patterns which can be used by both practitioners and academics. The research will also help determine the future research areas in the field.
\end{abstract}

Keywords: Social media, Engagement, Communication strategies

\section{Introduction}

The communication pattern between consumers and companies have transformed significantly with the introduction of popular social media platforms (Bergen, 2014). Rapp et al. (2013), showed that $88 \%$ of the companies in media, IT and telecommunication, FMCG and retail, travel and leisure have already strong presence in many social media platforms according to their marketing strategies 
starting from Facebook, Twitter and YouTube (Nisar and Whitehead, 2016. Making social media a mainstream media platform connecting one-third of the world's population (Nelson-Field and Taylor, 2012). As it is an efficient way to find new customers and to maintain, retain the existing customers (Luo et al., 2015) the basic marketing goals. So, social media sites became one of the most important touchpoints with the consumers for every brand. The researches in this area also showed that the social media presence leads to better business business performance (Quinton and Wilson, 2016). The products specifications and quality are shaped according the needs and expectations of customers using social media (Fiore et al., 2016).

There is a little research on the understanding of social media communication and how it can be used to engage the consumers especially by the dairy industry.

The relationship between the consumer and the brand relationships through social media platforms needs to be investigated to understand dairy products brand efforts and to shed light to the structure of the data available, the design and delivery of social media content in the dairy industry.

This paper tries to guide further academic investigation on the topics of social media and especially the consumer engagement in the dairy industry using social media data available through Facebook. The paper will add to the knowledge in social media and engagement by identifying the main communication strategies used by dairy brands on Facebook, emphasizing valuable statistics and trends regarding engagement rates and patterns on related pages which can be used by both practitioners and academics for benchmarking in further academic works. The research will also help determine the future research areas in the field.

\section{Literature Review}

The change in communication scheme has now become "many to many" and networks shifted the power towards the consumers. The consumers became

active participants in the brand message instead of being passive receivers (Mangold and Faulds, 2009). This change has also modified the information acquisition, purchase behaviour and postpurchase communication of consumers making them brand advocates or innovators for the brand making social media presence a valuable asset for the companies (Chu and Kim, 2011; Vivek et al., 2012)

Scholars have adressed more attention to the aspects of this phenomenon such as the usage motivations of participants (Joinson, 2008), social interactions, usage patterns (Golder et al., 2007; Hsu and Lin, 2008), the characteristics of users (Gjoka et al., 2008; Hargittai, 2007), the on online and virtual brand communities, online brand culture (Schembri and Latimer, 2016) and anti-brand community behaviours (Dessart et al., 2016). The role of social media presence in communication strategy in the dairy products industry is however less investigated.The design of their social media content in this industry with the best practice for marketing activities within the social network sphere needs to be clarified.

Looking towards the customer side of social media, academic attention has focussed on categorising social media users and 'users' of online communities, distinguishing between users who create content and who are passive users, referred to as 'lurkers' (Nonnecke and Preece, 1999; Preece et al., 2004). This basic categorisation of online users is limited however there are many roles available for users in these dynamic social media platforms. Previous research categorised online consumers 
based on their brand loyalty, brand love, use of self-expressive brands and word of mouth (Wallace et al., 2014) taking into account their engagement intensity on a continuum of low to high activity (Muntinga et al., 2011) and valence (Dolan, 2016).

This categorisation scheme is justified by consumers who interact with the companies through many points, product/service (Brodie et al., 2011), media (Calder et al., 2009) and special events (Vivek et al., 2012) but we consider the context of a social media platform and the engagement of the consumer showing the consumer's creation, contribution, or consumption of brand-related content in the social media platform. As suggested by Malthouse et al. (2013) the degree of engagement varies, from basic engagement such as "liking" a page on Facebook to higher forms of engagement such as "writing reviews" and possible co-creation activities in both positive and negative valence as the consumer can also use these platforms to complain and destruct brand value (Bijmolt et al., 2010; Harris et al., 2010).

The value and potential of social media engagement is shown in the practice by the integration of social media platforms to the marketing mix (Stelzner, 2014; Sinclair, 2014; Bergen, 2014). Especially, for the dairy industry where competition is fierce and the brand perception plays an important role, the brands compete to attract and retain consumers, many are embracing social media to reach their consumers and communicate their brand quality and personality. Because, with a population of 80 million people, predicted to increase to over 82 million by 2021, Turkey is an important market for dairy companies. The Turkish dairy market is growing fast with predicted $63 \mathrm{~kg}$ per person consumption in 2021.

The majority of Dairy products are sold through hypermarkets and supermarkets followed by foodservice and convenience stores. Rapidly increasing urbanization, a large young population and growing income levels are increasing consumption of dairy products in Turkey. New healthier products are becoming a key growth factor for this industry. Accordingly, social media is particularly effective among consumers, as word of mouth about these new products is an important driver of sales. Due to the socialisation aspect of social media, consumers exchange information and encourage others to try these new products.

The fact that many brands in the dairy sector use social media to interact with consumers is not surprising; however, many practitioners have identified a lack of awareness and knowledge regarding effective social media strategy. This includes a significant concern regarding understanding exactly how and when customers might engage with posts. To contribute to a deeper understanding of social media strategies and user engagement behaviours within the dairy sector,

this paper focusses on three main research objectives and the resultant contributions surrounding social media strategy. Specifically, through this research we will try to identify the main communication strategies of the dairy sector, show the engagement benchmarking statistics of consumers using Facebook as a social media platform and try to understand the engagement patterns in the dairy sector to understand their marketing efforts and to provide insights on the design and delivery of social media content in this industry.

\section{Methodolgy}

The purpose of this paper is to shed light on brand communication strategies of companies in dairy industry on Facebook. One of the goals of social media brand strategies is to engage the users so we 
used the engagement metrics and rates to explore the trends in social media brand communication strategies to help future campaigns and develop future research areas. In order to do this, we focused on the data from 6 companies Facebook pages over 4 months beginning on 1 March and concluding on 30 June 2018. We used Facebook Insights data from active Facebook brand pages in the Turkish Dairy Market Companies. Facebook Insights with the administrators permission of brands enabled us high-level monitoring of the activities that occur on that page including the data concerning the performance of a post, such as the number of people the post reached, the number of people who clicked the post and the number of people who liked, commented on or shared the post. If the post is a video, Insights data also shows the total number of video views, and length of video views. Insights data provides also the engagement rate defined as the percentage of people who saw a post and liked, shared, clicked or commented on it.

The 6 brands were selected to ensure a representative sample of the industry according to the number of fans, region, and frequency of posting. The total number of posts in the data set was 1.090. The total number of fans across the 6 brand pages at the beginning of the research period was 24.632 and reached 25,812 at the end of the period.

The total of 6 Facebook Insights data files and corresponding engagement metrics for each post were analyzed using SPSS Statistics. Using the Neuendorf (2002) quantitative content analysis method, Dolan et al. (2015) coding frame, 1.090 posts were coded for their level of each type of content.

\section{Research Findings}

The analyse of the posts revealed that $74.6 \%$ of the posts contained informational content, $42 \%$ entertaining content, $10.1 \%$ remunerative content and $60.1 \%$ relational content. With some posts having two types of content together and with varying content loads in one type of content.

The results show that the most popular types of informational content used were links to the website (17\%), product images (15\%) and details about the product (12\%).

Concerning the entertaining content, the most common type was the provision of images of events, which were evident in $20 \%$ of total posts. Remunerative content was used to a much lesser extent $5 \%$ and the most popular type of remunerative content was deals and special offers. The relational content was however commonly used by the companies with $25 \%$ within the posts mentioning the kids and the family.

In addition, the trends regarding the type of post were also analyzed. Types of posts categorised were text only post, photos and videos. The most common

type of post was the use of photos. The brands used a total of 765 photos (70\% of posts), 312 status updates and only 31 posts were videos. Accordingly, photos have the highest average number of comments (four comments), and the highest average number of likes (33 likes) and a slightly higher average number of shares (two shares) than posts that are status updates or videos. This highlights the need to work for better engagement rates.significant challenges for marketing managers responsible for stimulating heightened engagement through their Facebook content.

The engagement for the entire data set, irrespective of the type of the post, post time of the day or post day of the week shows that less than 1 per cent of users who see the Facebook post, make a comment. The highest number of comments a post received was 47. Posts receive on average 20 'likes', which represented 3 per cent of people who saw the post in their news feed. On average, 
posts are shared two times, within a maximum of 24 shares achieved. So, this is a very low level engagement, representing less than one per cent of the total users reached and only 10 per cent of users who see a post from a dairy brand in their news feed engage by actions such as commenting, liking, sharing, watching video, clicking on the post, viewing photos, hiding post, reporting posts or un-liking the page.

Similarly, previous research have also shown poor online engagement rates, with an average of 0.07 per cent of Facebook fans interacting with a brand's post (e.g. Gayomali, 2014). This shows the difficult challenge for marketers to stimulate higher engagement rates amongst fans.

Previous studies have found that users are more active on Facebook brands pages during workdays (Golder et al., 2007). These studies also show that click through rates of online advertisements decrease significantly on weekends, and users do less internet searching during weekends (Rutz and Bucklin, 2011). Accordingly, our results indicate that the lowest level (4\%) of activity in terms of number of posts delivered by the brands over a seven-day period occurred on Sundays, while the highest number of posts were shared on Tuesdays with 218 occurrences (20\%).

A comparison of engagement actions across the days of the week provides important results, the average number of shares made on a post is significantly higher on Wednesdays. The average number of comments made on a post remains relatively stable across each day of the week. The average number of likes made on a post is relatively consistent across each day of the week. Similarly, the average number of times a link is clicked on is consistently low regardless of the day of the week. The average number of times a photo is viewed is higher on a Tuesday.

The time schedule within the day shows that users engage less during the morning and their activity increases towards the evening, reaching high level during the night (Golder et al., 2007). So, it is good to post for the brands when Facebook users are more active, to be seen on the wall. However, brands rarely deliver their posts at this time of the day. This difference between post scheduling and peak engagement times illustrates a potential lack of knowledge on the part of practitioners regarding the best opportunities for their social media presence.

\section{Results}

According to Dolan et al. (2015), model the four social media content categories of informational, entertaining, remunerative and relational content are applied in this work on dairy products industry. Over 70 per cent of dairy brand posts include informational content, it's the most common type of content and it' posted in the form of a photo. Entertaining content is also used largely. Despite the literature where the discounts and economic incentives (Muntinga et al., 2011; Cvijikj and Michahelles, 2013), is important, only ten percent of the posts contained remunerative details. So, the promotion and discounts are rarely used by the sector. The relational goals are also followed by companies as they are willing to integrate the users to the discussions and make them active users.

Turkish dairy producers generally use status updates and photos in their posts, however very rarely use videos. This may be due to a lack of expertise regarding filming processes, an uncertainty regarding what to film and maybe professional filming costs. However, the only text form and especially the text with photo form of posts are largely used although the videos provide more engagement activities and 'likes'. The passive users have to be stimulated as suggested by NelsonField and Taylor (2012) as they are the majority of users. 
INTERNATIONAL JOURNAL OF ACADEMIC RESEARCH IN BUSINESS AND SOCIAL SCIENCES

Vol. 8, No. 12, Dec, 2018, E-ISSN: 2222-6990 C 2018 HRMARS

Concerning the time schedule, the results of the study are consistent with previous studies (Golder et al., 2007; Rutz and Bucklin, 2011). The posting day of companies 'Tuesdays' show that marketers are consistent with the findings in previous and this study.

\section{Conclusions and Future Research}

The social media communication strategies of Turkish dairy companies are identified, the findings of the study can be used by both practitioners and academics. The trends in posting patterns of companies and users habits according to time schedule is investigated using previous researches models. The study showed the four typical practice goals of companies and the posting day and format of companies. A similar analysis is provided for hours of the day to find more effective formats and hours that will push users to be more active and to engage them to like, and share. These results are confirmed by previous works and 'Tuesdays' are added to the literature as the most practiced day for posting activities.

The study leads to the development of two questions to be included in future research agenda starting with the analysis of drivers of engagement and the measurement of social media content effectiveness. Future research on these issues can enhance our understanding of delivering effectively social media content to facilitate increased engagement amongst users, and leading to enhanced customer value.

\section{Acknowledgement}

This work was supported by Galatasaray University, Scientific Research Projects Commission under project number 18.102.006. The authors are grateful for the support.

\section{Corresponding Author}

Caner DINCER, Faculty of Economic and Administrative Sciences, Department of Business Administration, Galatasaray University, Turkey. Email: cdincer@gsu.edu.tr

\section{References}

Bergen, M. (2014), "Ad age survey: how advertisers are spending on Facebook, Twitter and YouTube", Ad Age, available at: http://adage.com/article/digital/ad-age-reader-survey-twitter-facebookyoutube/293923/2014

Bijmolt, T.H., Leeflang, P.S., Block, F., Eisenbeiss, M., Hardie, B.G., Lemmens, A. and Saffert, P. (2010), "Analytics for customer engagement", Journal of Service Research, Vol. 13 No. 3, pp. 341-356.

Brodie, R.J., Hollebeek, L., Jurić, B. and Ilić, A. (2011), “Customer engagement conceptual domain, fundamental propositions, and implications for research", Journal of Service Research, Vol. 14 No. 3, pp. 252-271.

Calder, B.J., Malthouse, E.C. and Schaedel, U. (2009), "An experimental study of the relationship between online engagement and advertising effectiveness", Journal of Interactive Marketing, Vol. 23 No. 4, pp. 321-331

Chu, S.C. and Kim, Y. (2011), "Determinants of consumer engagement in electronic word-of-mouth (eWOM) in social networking sites", International Journal of Advertising, Vol. 30 No. 1, pp. 47-75. 
INTERNATIONAL JOURNAL OF ACADEMIC RESEARCH IN BUSINESS AND SOCIAL SCIENCES Vol. 8, No. 12, Dec, 2018, E-ISSN: 2222-6990 @ 2018 HRMARS

Cvijikj, I.P. and Michahelles, F. (2013), "Online engagement factors on Facebook brand pages”, Social Network Analysis and Mining, Vol. 3, pp. 843-861.

Dessart, L., Morgan-Thomas, A. and Veloutsou, C. (2016), "what drives anti-brand community behaviours: an examination of online hate of technology brands", Let's Get Engaged! Crossing the Threshold of Marketing's Engagement Era, Springer, New York, NY.

Dolan, R., Conduit, J. and Fahy, J. (2016), "social media engagement: a construct of positively and negatively valenced engagement behaviours", in Brodie, R.J., Hollebeek, L. and Conduit, J. (Eds), Customer Engagement: Contemporary Issues and Challenges, Routledge, New York, NY.

Dolan, R., Conduit, J., Fahy, J. and Goodman, S. (2015), "Social media engagement behaviour: a uses and gratifications perspective", Journal of Strategic Marketing, Vol. 13 No. 4, pp. 1-17.

Fiore, M., Vrontis, D., Silvestri, R. and Contò, F. (2016), "Social media and societal marketing: a path for a better wine?", Journal of Promotion Management, Vol. 22 No. 2, pp. 268-279.

Gjoka, M., Sirivianos, M., Markopoulou, A. and Yang, X. (2008), "Poking Facebook: characterization of osn applications", Proceedings of the First Workshop on Online Social Networks, ACM, pp. 31-36. Golder, S.A., Wilkinson, D.M. and Huberman, B.A. (2007), "Rhythms of social interaction: messaging within a massive online network", Communities and Technologies, Springer, New York, NY.

Hargittai, E. (2007), "Whose space? Differences among users and non-users of social network sites", Journal of Computer-Mediated Communication, Vol. 13 No. 1, pp. 276-297.

Harris, L., Russell-Bennett, R., Plé, L. and Chumpitaz Cáceres, R. (2010), “Not always co-creation: introducing interactional co-destruction of value in service-dominant logic", Journal of Services Marketing, Vol. 24 No. 6, pp. 430-437.

Hsu, C.L. and Lin, J.C.C. (2008), "Acceptance of blog usage: the roles of technology acceptance, social influence and knowledge sharing motivation", Information \& Management, Vol. 45 No. 1, pp. 65-74. Joinson, A.N. (2008), "Looking at, looking up or keeping up with people?: motives and use of facebook", Proceeding of the Twenty-Sixth Annual SIGCHI Conference on Human Factors in Computing Systems, ACM, Florence.

Mangold, W.G. and Faulds, D.J. (2009), "Social media: the new hybrid element of the promotion mix", Business Horizons, Vol. 52 No. 4, pp. 357-365.

Malthouse, E.C., Haenlein, M., Skiera, B., Wege, E. and Zhang, M. (2013), "Managing customer relationships in the social media era: introducing the social CRM house", Journal of Interactive Marketing, Vol. 27 No. 4, pp. 270-280.

Muntinga, D.G., Moorman, M. and Smit, E.G. (2011), "Introducing COBRAs", International Journal of Advertising, Vol. 30 No. 1, pp. 13-46.

Nelson-Field, K. and Taylor, J. (2012), “Facebook fans: a fan for life?”, Admap: Warc.

Neuendorf, K.A. (2002), The Content Analysis Guidebook, Sage Publications, Thousand Oaks, CA.

Nonnecke, B. and Preece, J. (1999), "Shedding light on lurkers in online communities", Ethnographic Studies in Real and Virtual Environments: Inhabited Information Spaces and Connected Communities, Edinburgh, pp. 123-128

Preece, J., Nonnecke, B. and Andrews, D. (2004), "The top five reasons for lurking: improving community experiences for everyone", Computers in Human Behavior, Vol. 20 No. 2, pp. 201-223. 
Quinton, S. and Wilson, D. (2016), "Tensions and ties in social media networks: towards a model of understanding business relationship development and business performance enhancement through the use of LinkedIn", Industrial Marketing Management, Vol. 54 No. 1, pp. 15-24.

Rutz, O.J. and Bucklin, R.E. (2011), "From generic to branded: a model of spillover in paid search advertising", Journal of Marketing Research, Vol. 48 No. 1, pp. 87-102.

Schembri, S. and Latimer, L. (2016), "Online brand communities: constructing and co-constructing brand culture", Journal of Marketing Management, Vol. 66 No. 1, pp. 1-24.

Sinclair, L. (2014), "Spending on digital marketing to outstrip traditional channels: study", The Australian, Sydney.

Vivek, S.D., Beatty, S.E. and Morgan, R.M. (2012), "Customer engagement: exploring customer relationships beyond purchase", Journal of Marketing Theory \& Practice, Vol. 20 No. 2, pp. 122-146. Wallace, E., Buil, I., De Chernatony, L. and Hogan, M. (2014), "Who likes you and why? A typology of Facebook fans", Journal of Advertising Research, Vol. 54 No. 1. 